\title{
Configurations of self-identity formations of adults who stutter
}

\author{
Harsha Kathard \\ Vivienne Norman \\ Mershen Pillay \\ School of Health and Rehabilitation Sciences, University of Cape Town \\ Correspondence to: H Kathard (Harsha.Kathard@uct.ac.za)
}

\begin{abstract}
It is important for clinicians to understand how adults who stutter construct who they are, i.e. their self-identity, in order to offer personally meaningful interventions. Early research on stuttering and self-concept provided initial knowledge, but there has been a dearth of further research in this field. This article, the third in a series of papers emanating from a doctoral study, provides new insight into the configurations of self-identity formations of adults who stutter. Previous articles from the study described how 'Able' (positive self-identity) and 'DisOther' (negative self-identity) self-identity formations developed over time. This paper describes the configurations of self-identities, Able and DisOther, evident across participants' stories. The study used a life-history methodology in which 7 adult participants ( 5 men and 2 women) shared their experiences of living with stuttering through open-ended interviews. The data from the interviews were analysed at two levels. The first level of analysis resulted in a description of the types of self-identity formations (positive and negative) and processes (personal, social and temporal) shaping the self-identity formations. This result was represented as a research story for each participant. The second level of analysis described the configurations of the self-identities, Able and DisOther, across the research stories. The main findings, illustrated through three research stories, were that the two types of self-identity formations, Able and DisOther, were present in singular and dual configurations. The dual presentation of self-identity formations occurred in co-existing, competing and coalescing configurations at particular time periods, illuminating the complexity of the stuttering experience. The clinical implications are discussed.
\end{abstract}

Keywords: life-history methodology, self-identity configurations, stuttering

Clinicians require a close understanding of the experience of stuttering in order to offer meaningful and personally relevant interventions for adults who stutter. The individual's unique experience of stuttering can be revealed through understanding how they construct themselves, i.e. their self-identity. Silverman (2001) encouraged growth of researchers' scientific repertoires and argued that when a person who stuttered sought help, he/she did so as a whole person who lived in complex ways with stuttering. Silverman's plea for such personal knowledge was a result of her observation that research which was reduced to numbers and facts had little practical value for the clinician. Noting this methodological and conceptual gap in research, the study (Kathard, 2003) upon which this article is based, examined how adults who stutter made sense of themselves, having lived with stuttering since childhood.

Kathard's study (2003) was preceded by studies that emphasised the importance of understanding self and stuttering (Fransella, 1968, 1972; Shearer, 1961; Sheehan, 1970). These early theorists offered varied explanations about self, self-construction and stuttering and applied them to interventions. Sheehan (1970) explained stuttering by using 'role-conflict' theory and considered it as a role-specific behaviour. In his view stutterers have dichotomised understandings of themselves (in role as fluent speaker and role as stutterer). As a consequence of living with stuttering over a prolonged period, they developed understandings of themselves as stutterers rather than as fluent speakers, and this role was resistant to change. While he argued that an acceptance of selfconcept in a stutterer role was important at an initial stage of treatment, it was expected that by the end of an intervention the stutterer would accept himself as a normal speaker by seeing himself in a fluent speaker role. The intervention therefore required a radical reinvention of self to that of a normal speaker.

Shearer (1961) also described stutterers as having dichotomised and conflicting self-concepts - 'a horrible stuttering self' and a 'free-speaking normal self' (p. 115). The intervention was directed at reconciling these conflicting self-concepts with the intention of achieving a free-speaking normal self. He added that relapse occurred when the stutterer no longer perceived him/herself as a stutterer and therefore did not monitor his/ her speech and the environmental cues which elicit stuttering.

Fransella (1968) investigated the self-concept of a stutterer as a person using Kelly's personal construct theory (PCT). Kelly (1955) made three important contributions that have relevance for this study. Firstly, he argued that in order to understand the human condition and behaviour, one has to understand it from the vantage point of the person living with that behaviour - the insider view. Secondly, when a person makes sense of him/herself he/she does so by generating self-constructs which occur as a network of constructs in relationship with each other. Thirdly, he coined the term 'constructive alternativism' which elucidated the idea that people have alternatives in how they choose to construct themselves, e.g. fat/thin, happy/sad. The process of successful change is achieved when a person is able to construct an alternative understanding of him/herself as the basis for effecting the necessary behaviour change.

Fransella (1968) investigated how the person who stutters constructed him/herself as a person using a combination of repertory grid and semantic differential techniques. Using this method, she reported that stutterers have two primary understandings of themselves - as an individual and as a speaker. Firstly, as an individual he/she is unique and different to all other people, including those who stutter. Secondly, as a speaker, he/she holds the negative stereotypical view of themselves as stutterers. The intervention was therefore aimed at helping the stutterer as a speaker to develop a network of self-constructs to revise his/her selfconstruction to that of a fluent speaker and to experiment with fluency.

Fransella (1972) further tested her hypothesis that stuttering would decrease as the person took on the fluent speaker role. Intervention focused on improving the meaningfulness of the fluent speaking role, rather than improving fluency, in adults with developmental stuttering. Her hypothesis was confirmed and this strengthened the impetus for self-reconstruction as a basis for achieving improved fluency. Evesham and Fransella (1985) were also concerned about relapse and hypothesised that stutterers were less likely to relapse if they were able to construct themselves as fluent speakers. They tested their hypothesis with a group of 48 participants who received fluency training in the first week of intervention. Participants were then divided into a technique group - intervention focused on prolonged speech techniques - and a PCT group who were assisted in reconstructing their fluent speaker role. While all subjects improved their fluency, it was concluded that the PCT group had a lower relapse rate (measured by fluency) than the technique group. Despite the reported benefit of PCT in fluency intervention by Evesham and Fransella (1985) and support from 
Stewart and Birdsall (2001), PCT did not have prominence in the US literature (DiLollo, Niemeyer \& Manning, 2002).

While the value of self-reconstruction as a basis for change is recognised in stuttering research, it is also evident that most interventions require the stutterer to take on a fluent speaker role or self-reconstruction as a fluent speaker with intention to improve fluency. Although Fransella (1968) acknowledged that stutterers had self-constructions of themselves as unique beings, her intervention did not build on these attributes but was directed instead towards self-reconstruction as a fluent speaker.

Kathard's (2003) study added to the knowledge base by approaching the study of self-identity as the basis for understanding the personal experience of stuttering. It differed from prior studies on self as it focused on describing the development of self-identity formations as well as the personal, social and temporal processes shaping these selfidentity formations in adults living with developmental stuttering. To achieve this, a purposefully created self-identity theoretical framework coupled with a narrative life history methodology was used.

The theoretical framework differentiated between role and selfidentities. While people play many different roles they only become 'identities' when people internalise understandings of themselves (Mishler, 1999), i.e. an identity of being a stutterer only occurs when the individual attaches such meaning to him/herself. These self-identities are constructed from different subject or 'I' positions, e.g. as a child at school, as a child at play, as an adult in a meeting, emphasising that identity formations are constructed from several subjective positions which vary across contexts, relationships and over time (Somers, 1994). A person may also construct more than one self-identity of himself/ herself. Critical to this paper is the understanding that self-identities are also dialogic, i.e. when an individual has more than one self-identity, these identities occur in varying relationships to each other and may be, for example, in conflictual or co-operative relationships (Hermans, 2002), with power dynamics between them influencing their relative dominance.

Previous studies have taken primarily a psychological approach to self-identity formation. This study combined the 'bodily' experience of stuttering, the thoughts, feelings, actions and motivations (psychological), as well as the social and temporal processes that influence identity formation. The social processes highlight how self-identity is shaped by social values and actions evident in daily interactions with family, friends, schools and other social institutions. Simply put, if people who are significant in one's life construct stuttering as a bad thing and broader society holds a similar view, then the person who stutters may internalise this negative influence.

It was also acknowledged that lives are dynamic and over time an individual may develop new or revised understandings of themselves. These changing formations suggest that self-identities are always in 'process' of developing from past to present and through to the future (Mishler, 1999). Over time, self-identities could be stable or flexible (Valsiner, 2002) as they are shaped by changing social and personal dynamics in everyday circumstances.

A qualitative, narrative life-history methodology was best suited to research self-identity formations within the framework described above. Qualitative research in general has gained popularity in communication science research because it offers varied research approaches, all of which are analytical by nature and systematic in their execution (Cresswell \& Miller, 2000). Such research is valuable in communication disorders because it seeks to understand complex, sociocultural phenomena through exploration, generates rich descriptive data, encourages a focus on individuals in context, and values the participant's point of view (DiLollo \& Wolter, 2004; Tetnowski \& Damico, 2001).

A narrative, story-telling approach was used because stories are considered the best way to understand experience (Clandinin \& Connelly, 1994). In telling their story, individuals combine their past actions and life events into a whole narrative form (Polkinghorne, 1996) which illuminates their self-identity. The self-story is ideal because it reveals fuller life configurations, weaving together bodily/ stuttering experiences, emotions, thoughts, contexts, actions, social systems, power and values. Participants use words combined as whole, meaningful stories, considered as valid data in studies of self-identity (Plummer, 2001). The life-history orientation was applicable because it provided the opportunity to obtain first-hand, retrospective, historical accounts of individuals' personal experiences (Hatch \& Wisniewski, 1995; Plummer, 2001). Narrative methodology also allows the participant the freedom to construct him/herself against the dominant discourses influenced by the medical model which traditionally present a view of living with impairment as a personal tragedy.

This article is the third in a series of articles emanating from the Kathard (2003) study. The first article (Kathard, Pillay, Samuel \& Reddy, 2004) described the processes shaping the negative self-identity as 'DisOther'. The term was coined to explain an individual's self-identity as different or 'Other', specifically on the basis of stuttering as a (Dis)order. The term (Other), appropriated from postcolonial studies (Boehmer, 1995), is a relational concept in which the individual constructs him/herself as different (Other) in a negative way. This negative self-identity and strategies for self-management were similar to those described in previous studies (Fransella, 1968; Petrunik \& Shearing, 1983; Shearer, 1961; Sheehan, 1970). Interrelated social processes (e.g. labelling, norming, judging) combined with personal processes (e.g. discoveries of difference; negative self-judgement, self-colonisation) and temporal burdening resulted in the strengthening and sedimenting of selfidentity as DisOther. The article also highlighted the importance of factors such as gender, race, culture and stuttering which intersect in self-construction.

In the second article in the series Kathard (2006) describes the processes underlying the discrete formation of the positive self-identity as Able, similar to self as a unique being referred to by Fransella (1968). Selfidentity as Able was based on participants' positive sense of self as a fuller human being and was not confined to a self-limiting description related to stuttering. Participants strengthened and reinforced selfidentity as Able by using enabling philosophies for self-development; resourcing themselves to create advantage, broadening their framework for communication and how to enhance it; and developing emotional literacy, personal acceptance of themselves and creating counternarratives. The multiple processes leading to strengthening self-identity as Able included improving communication and fluency, but were not limited to it.

While previous articles described the processes shaping the discrete self-identity formations Able and DisOther, the aim of this paper is to describe the varying configurations of these self-identity formations evident across the research stories of participants in the study. Given the word limitations for this manuscript, excerpts are drawn from three research stories which provide robust illustrations of the findings.

\section{Method \\ Participants}

Participants were recruited through a local stuttering self-help group, hospital-based speech-language pathology units, private practices and general public notices. Purposive sampling was used to select those with information-rich stories (Plummer, 2001). Criteria for inclusion were that they: (i) had stuttered since early childhood; (ii) had informationrich life stories; (iii) were willing to share their stories in English or the language of their choice; and (iv) were able to commit to prolonged engagement with the researcher through a minimum of three in-depth interviews. A fluency assessment was conducted by a qualified speechlanguage therapist at the university clinic to confirm the presence of developmental stuttering, and a brief screening interview ensured that participants had information-rich stories. Information-rich stories were those which had details about critical events, were contextualised, and had the necessary personal, temporal and social elements. Five men and two women of varied race, age, social and occupational backgrounds 
were selected to participate in the original study (Kathard, 2003). However, excerpts from three of those participants were included in this article to illustrate the results within the word limits of the manuscript.

\section{Procedure}

The research process was explained and written consent to participate was obtained before the in-depth individual interviews (Rubin \& Rubin, 1995). During these life-history interviews the researcher created open-ended opportunities for participants to share stories about their experiences with stuttering throughout their lifespan to achieve an in-depth and interconnected understanding (Samuel, 2009) of their nuanced life experiences. The interviews were not intended to focus on therapy experiences, unless relevant to the individual's experience. A significant effort was made to develop a respectful and trusting research relationship (Measor \& Sikes, 1992), to create an environment conducive to truthful personal story-telling. Because participants stuttered, the researcher and participants discussed ways to promote easy and respectful communication (Kathard, 2009) during the interviews. Indepth interviewing was achieved using a series of matrix-like probes to explore personal, social and temporal (Kathard et al., 2004) aspects of their story systematically. Participants were also encouraged to provide additional documents (e.g. letters, diaries), support material (e.g. video recordings) and artefacts (certificates, photos) to reinforce the authenticity and depth of the story-telling process. Two senior researchers evaluated each recorded interview and made suggestions for enhancing the quality of interviews. Their suggestions included strategies for enhancing appreciative listening, ways to allow the story to unfold freely, and the strategic use of probes.

All participants were interviewed at least three times with each interview lasting approximately 2 hours. The total interview time for each participant ranged from 6 to 10 hours. The researcher engaged with participants over a period of 1 year for the purposes of data collection, review of stories and analysis. All interviews were audio-recorded, transcribed verbatim, checked for accuracy by the researcher and research assistant, and verified by a senior researcher. The study received ethical approval from the University of Durban-Westville Ethic Committee. Pseudonyms have been used to ensure participants' anonymity.

\section{Data analysis}

The first level of analysis was representational narrative analysis (Freeman, 1996; Polkinghorne, 1996). In this process the interview data (raw data) were analysed in relation to the research question and represented as a biographical research story for each participant. A thick description of the participant's context was embedded in the research story. This description allowed the researcher to capture detail, density and depth of the individual experience, thereby allowing the reader the opportunity to feel that he/she understood the experience (Charmaz, 1995; Plummer, 2001). The stories characterised individuals, described emotions and actions, and located individuals in specific social and temporal contexts.

The research story was a good representation device because it integrated the types, processes and configurations of self-identity formations. The task of the researcher was to ensure authentic and fair interpretation of the individual's experience. It is well recognised that the storied experience is unlikely to mirror the actual experience. Therefore, further steps were taken to ensure that the research story represented personal truth as accurately as possible. Each participant therefore critiqued his/ her personal research story and suggested changes to make the story a closer representation of their experience.

The second level of analysis involved a detailed analysis of research stories into the themes related to the configurations of self-identity formations. The themes were generated through a process of constant comparison between and within cases (Miles \& Huberman, 1994). In this paper excerpts from the research stories (first-level analysis) are combined with the second level thematic analysis across stories.

\section{Rigour and trustworthiness}

The rigour and trustworthiness of the study were enhanced through various substantive and ethical validating processes (Angen, 2000) applicable to qualitative narrative research. Substantive validation was firstly achieved by evaluating the suitability of the methodology in relation to the research question. The choice of life-history methodology was clearly applicable to this study as it was able to generate robust data to understand self-identity formations. Secondly, various measures were in place to ensure that the study was credible (Lincoln \& Guba, 1985). Credibility of the data collection process was enhanced through in-depth interviewing, member-checking, prolonged engagement, and peer review and debriefing (Cresswell \& Miller, 2000). Further to member-checking during the interview process, the research stories were also presented to participants to ensure that their experiences were truthfully represented. Peer-review and debriefing was conducted throughout the research process (Lincoln \& Guba, 1985). The researcher, assisted by senior researchers, reflected critically on the process before and after each interview to ensure that her own thoughts and opinions were kept in check. The depth of story telling was enhanced by prolonged engagement (Plummer, 2001). In addition to the minimum of three indepth interviews with participants, two additional contacts were made during the analysis process. Contact with participants was sustained for approximately a year, allowing the researcher and participants the opportunity for critical reflection and refined data collection. This process also assisted in the development of a trusting relationship, so that sensitive aspects of the story could be probed over time.

While triangulation for the purposes of verification (Begley, 1996) was not applicable to this study (i.e. personal truth could not be verified through any other method other than personal story-telling), the relevance of triangulation for the purposes of completeness of analysis was considered. The researcher's analysis of self-identities as the unit of analysis was strengthened by the input of two experienced life-history researchers of different theoretical backgrounds. One expert considered the validity of the analysis of self-identity formations from a disability and impairment perspective, while the other reviewed the plausibility of interpretation from a psychosocial theoretical standpoint. This process assisted in achieving a unit of analysis triangulation (Knafl \& Breitmayer, 1991). Ethical validation required that several ethical issues relevant to the methodology were considered. For example, the researcher was cognisant of potential power imbalances between the researcher and participant (Kathard, 2009), only used authorised information in research stories and took the necessary steps to ensure that participants' stories were fairly represented.

\section{Results and discussion}

The findings on the configurations of self-identity formations Able and DisOther occurring across the research stories are presented. A brief overview of the configurations within the stories is also provided at the end of the results section. Owing to the word limits of the manuscript, excerpts from the stories of only three of these participants are used to illustrate the findings. Data excerpts in this paper are from Kathard (2003) and also appear in Kathard et al. (2004) and Kathard (2006).

The biographical profiles of participants in the three stories used in this paper are as follows:

Gareth, a 65-year-old white man, is a retired architect with a university degree. He rated his stuttering as mild at the time of the interview, which correlated with the clinician's rating. He attended speech therapy weekly for approximately 3 months when he was at primary school. His father and brother were disfluent but were not diagnosed with stuttering.

Hennie, a 29-year-old white man, is an accountant with a university degree. He rated his stuttering as moderate to severe, which concurred with the clinician's rating of severity at the time of the interview. Hennie had attended the university speech therapy clinic for 6 months at the time of the interview. There was no family history of stuttering. 
Kumari, a 36-year-old Indian woman, is an accountant. She rated her stuttering as mild at the time of the interview, which concurred with the clinician's rating. She had never attended speech therapy.

\section{Singular self-identity formations}

At varying points in the stories, the singular self-identity formations (DisOther or Able) were evident. During her early years and throughout adulthood, Kumari retained a single, dominant self-understanding of herself as DisOther (Kathard et al., 2004):

Kumari: I stuttered when I was four. I was detached, isolated and lonely. I had friends, but no best friends because Rangini went to another school. My self-esteem was low. Rock bottom. I was fashioned out of fear ... I was a fearful, stuttering girl. I gorged on negativity and I couldn't connect with anyone. The void grew bigger as I grew older ... Even if I had a small, simple request like leaving a few minutes early from work, I set myself up for failure. I feel (my abusive father's) imposing presence. I am a child again, terrified. I stutter, radiate negativity.

In contrast, Hennie's story revealed a singular self-identity as being Able:

Hennie: The stuttering was never always such a big problem as it is now. I don't believe the stuttering, i.e. the speech and the blocks itself, has evolved or changed that much. My father never really punished us. They were easier-going than the rest. I really don't recall any talk or them being worried about my speech at that time. Life was very nice. Stuttering was there but I never let it rule my life. I was okay.

Hennie's dominant experience of being Able occurred in childhood. Although he stuttered as a child, stuttering received little negative meaning in his personal and social context. He did not attach negative meaning to stuttering in his early childhood years. Therefore, stuttering had little salience and his self-identity as Able was constructed on the basis of other positive life experiences. In contrast, Kumari's story during childhood indicated a singular and stable self-identity as DisOther, created through complex social and personal circumstances over time (Kathard et al., 2004). Her experience resulted in negative self-definition linked to stuttering as well as her early traumatic experience of abuse.

The prominence of a singular negative positioning of self in a world which is dynamic and changing may seem unlikely, yet Kumari's selfidentity as DisOther had been prevalent for many years of her life. These prolonged experiences of singular negative self-understanding resulted from conservative social and personal forces that act in the interests of minimising complexity, ambivalence and conflict (Hermans, 2002). This stable, albeit self-oppressive and rigid knowing of self, is favoured because it fits in with a hierarchical structuring of the world where children, women and people with impairments/disorder occupy lesser positions. In such instances, the self becomes less multi-voiced and more monological. When the disempowered self as DisOther is reinforced in this monological direction there is a loss of potentiality, and this results in a severe miniaturisation of human beings (Sen, 2006), i.e. people have diminished views of who they are.

In contrast, Hennie's self-identity as Able reveals that it is possible to live with stuttering without being negatively defined by it, as he constructs himself within a discourse of possibility. Hennie's story of positive self-identity is not uncommon in children who may not have internalised understandings of themselves in relation to stuttering. While participants' self-identities reflect their sense of stability about who they are during their childhood, Kumari's and Hennie's selfunderstandings were very different to each other.

Further to the singular identity formations, the stories also revealed dual self-identity configurations.

\section{Dual self-identity configurations}

\section{Co-existing self-identity formations}

Co-existing configurations occurred when both self-identity formations (Able and DisOther) were present in an individual's story over a particular time period, but were different across contexts. For example, in Gareth's story self-identity as Able was prominent on the playground while self-identity as DisOther was prominent in the classroom, as reported by Kathard et al. (2004).

Gareth in the classroom: At school I never got away with it altogether. The stutter was there and growing. I wanted to forget about it and be like everyone else or better than everyone else. But they wouldn't let you forget. We hear the dreaded footsteps marching down the corridor. They are two classes away, one class away, and then they are here. The threesome: the principal, the nurse and the school inspector. Society watchdogs! We knew what they were looking for, all the misfits, all the problems. Maybe they would forget about me. Then they start: come to the front when we call your name and problem; McDonald and Hastings - Head Lice; Smith - Can't See Well; Lovemore - Cripple; Blake - Stutterer. I just want to disappear into the ground. Is this all they know about me? Hey, remember I came second. They fill out the forms. I remain silent. Powerless. They make it unbearable. Everyone knows I am a stutterer, but this is a painful public display.

Gareth in the playground: Fortunately, there was always the other side and I gave as good as I got. Playground and friends were a real joy. I had a talent and passion for soccer. We get to the field, in teams. Captain: Gareth Blake. Coach: Gareth Blake. Manager: Gareth Blake. I am the team. They played in My Team. I hand out the carefully painted badges. I select the team, coach them, talk about the game plan and we play ball. We run, shout, kick and scream. Stuttering is furthest from my mind (Kathard, 2006)

Bakhtin (1981) explained that utterances which produce the story of the self come from a particular voice influenced by cultural circumstances and socio-political realities. In society, the power one has is derived in part from social, institutionalised power. For example, there is a relative socially inscribed power that men have over women, boss over worker, and teacher over learner. Endowed with socially inscribed power, Gareth feels more powerful as a team leader on the playground than in his position as a child who stutters being examined by school authorities. Self-identities are contextual and relational, and it is therefore possible to have different understandings of oneself across different contexts (Valsiner, 2002). It was possible for the participants to have understandings of themselves as both Able and DisOther existing fairly separately across contexts.

Given such fluidity, it is possible to construct self-identity differently across contexts, and therefore to experience stuttering and communication in varied ways across contexts. These multiple selfunderstandings challenge the singular, reductionist discourse promoted by the medical model, which defines the person by the impairment. It emphasises that human lives are plural (Sen, 2006), and that there are different ways of living with stuttering. The challenge, even within multidimensional theories of stuttering, is for clinicians and society in general to acknowledge these fluid, multiple, and co-existing selfidentity formations in order to transcend the idea that living with stuttering is necessarily a personal tragedy.

\section{Competing self-identity formations}

In the research stories self-identity formations Able and DisOther were sometimes both available in a given context. Each self-identity, underpinned by a particular set of beliefs and ideologies, competed for dominance within this context. The competing relationship and dialogue between the self-identities results in a struggle or conflict. Contexts and situations are dynamic, and therefore these competing configurations also fluctuate.

Hennie: Imagine this. I walk in the door, tall, blond, macho, strapping; rugby-playing Hennie. I am feeling fine. Next to me is the guy in the wheelchair. His problem is obvious. I look normal. I am OK for now [Feeling Able] I open my mouth to speak and ... NO. The game is not over yet. Not over till I stutter. Then it happens. Out of the blue. It takes me by surprise because I don't know exactly when it will pop up, and until it does 
I am normal. You're not in control of your mouth and that is it. (Kathard et al., 2004.)

So now a new struggle starts. I have to struggle from being a stutterer to get back to a normal. The only way I can do that is by not stuttering. Then that tune plays in my head. Don't stutter. Don't stutter. You battle on. Lean over to the normals, from the dark side. Lean back from the dark side to the normals, lean back again to the dark side. If you stop and choose silence you lose the race. So I persist. From dark to normal. Through all this you just hope that you can make them understand that there is more to this person than just the stutter. I am also another normal behind that abnormal stutter. There is still that normal man with the wit and knowledge to speak his mind. The worst is that sometimes I forget that normal man and then I am the abnormal. ABnormal.

Competing selves present in biographies gave a deeper sense of the complex experience of stuttering. The dialogue between selves, competing for prominence from different ideological positions (Salgado \& Hermans, 2005) created an internal communication fraught with struggle about 'Who am I?' within a given context. Given the dynamic nature of contexts, the selves are constantly positioned and repositioned moment by moment as the communication is negotiated strategically, giving a sense of the effort required in interaction. This 'unstable equilibrium' (James, 1982) is an emotionally draining experience, and therefore people must find ways to resolve such instability.

Viewed differently however, competing selves could be considered as a positive development because this configuration signals that the self has an alternative position, especially when working against a powerful negative self-identity. Sen (2006) explained that when the force of a bellicose identity, such as self as DisOther, is challenged by the competing self-identity, the illusion of a singular, dominant identity is disrupted, allowing recognition of other positive facets of human affiliation and enhancing the possibility of choice. This notion of dual self-identity is not new and aligns with Kelly's (1955) concept of constructive alternativism, i.e. people have alternative ways in which they can reconstruct themselves to enable processes of self-change which has been applied in stuttering intervention by Fransella (1968, 1972). However, this study does not only foreground the discrete selfconstructions but importantly the nuanced power struggle between these self-constructions.

\section{Coalescing self-identity formations}

In some stories there were harmonising relationships between the seemingly oppositional self-identities at particular points in the story.

Gareth: Through university I was a stutterer and having observed me in the studio presentations they would have said that's a stutterer. But down the line a different picture emerges. Gareth the architect, Gareth the father, Gareth the grandfather. Gareth the stutterer is still there but somewhere in the background. These days I give little attention to my speech and I speak to everyone. I have even become somewhat of a community spokesperson on the forums I sit on. There are just so many other things that occupy my mind now.

The self-identities appear to 'coalesce', suggesting that there was a harmonising relationship between them and an 'acceptance' of the selfidentity as DisOther. While it seems rather unlikely that a coalition of apparently different selves was possible, the stories suggest that it is. In a study of a 'coalition of opposites', Bhatia and Ram (2001) explain that an understanding of selves must transcend the simplistic pushpull metaphor. The ability to accept the self as both DisOther and Able appears to exist within a symbiotic relationship - one of ambivalence - within a loop that is dynamic in nature. Such ambivalence becomes a useful basis for negotiating different selves.

In the research stories participants seemed to negotiate living with stuttering successfully when they had accepted stuttering and negotiated their self as DisOther within their multi-voiced realities. This suggests that being able to bring disparate selves into a harmonising relationship is useful for living successfully with stuttering.

\section{Configurations within stories}

Although excerpts from the three stories have been chosen to illustrate the different configurations, it must be noted that each story has varied configurations over time. For example, while Hennie's story begins with his self-identity as Able, during school and university years and into adulthood he presented both co-existing and competing selfidentity formations. Gareth's self-identity formations changed over his lifespan. While he presented with competing self-identities in different situations in his school life, his experience did not suggest a single dominant negative self-identity at any point. In early adulthood his story revealed competing self-identity formations while in later adulthood he experienced a coalescing of self-identity formations. In contrast, Kumari had a self-identity as DisOther for many years of her life, and it was only in early adulthood that she began to develop her self-identity as Able.

Kumari: I gradually got to view many positive things about myself. Mind Power became a habit and my new way of living. I learned to trust my logic and intuition and began to recreate myself to become who I want to be.

Kumari's competing self-identity formation slowly gained dominance as she gradually reinvented herself in adulthood.

\section{Conclusion}

The findings across stories indicated that the configuration of the self-identity formations DisOther and Able occurred in singular and dual configurations. The dual configurations illuminated coexisting, competing, and coalescing relationships between selfidentity formations within and across research stories. These varied configurations highlighted the participants' subjective, fluid, multiple and complex understandings of themselves as they lived with stuttering over time. While the idea of positive and negative self-identity formations has already been introduced in this and other studies, the complex relationships between the self-identity formations illuminated in this study have important clinical implications.

\section{Clinical implications}

\section{Life-history interview in assessment}

For interventions to be personally meaningful, a thorough understanding of the client's experience of stuttering is necessary. This article described the varied configurations of self-identity formations, using the life-history interview. While it was used in this study as a research method, clinicians could use life-history interviews as a clinical method and engage each client in the personal telling of his/her story in the clinical assessment process. The case-history interview traces the history of stuttering, while the life-history interview invites the client to share how he/she has lived with stuttering in his/her social world over time. By taking this approach the client is co-opted into the assessment process and takes an active role in crafting and sharing his/her story, laying the foundations for participation in his/her own change process. In valuing this subjective/personal truth as legitimate knowledge the clinician gains a fuller empathetic understanding of the client's reality as a basis for an intervention that is personally meaningful (Hagstrom $\&$ Wertsch, 2004).

The techniques for conducting a life-history interview are described in detail in various life-history methodology texts. Applied to stuttering, the following strategies were found to be useful (Kathard, 2009):

- At the outset of the assessment the clinician must reassure the client that the intention of sharing his/her story is not to assess the frequency of stuttering or observe his/her struggle, but rather to hear the details about the experiences he/she thinks are most relevant. However, that he/she may block or struggle is likely and there should be an open negotiation about how communication breakdown on 
the part of the listener and speaker (e.g. long silences, interruptions, loss of eye contact) will be managed.

- Given that the intention is to hear the client's experience, the client has the freedom to select the issues he/she wants to talk about, in terms of events and critical moments which shaped his/her life most. The task of the clinician is to offer a non-directive space in which to generate the story and to listen deeply and non-judgementally. While the clinician can probe aspects of the story, he/she should not redirect the course of storytelling during the initial phase.

- The process may appear innocent and non-threatening, but it has potential to excavate truths that the client has masked or obliterated which may be unpleasant for him/her. The clinician should therefore be vigilant and proceed cautiously, allowing the client to share what he/she is comfortable with initially and other aspects of the story may emerge later in the process. For example, a person who experienced abuse as a child who stuttered may not talk about it at the initial stages of the process but may do so later when a secure relationship has been established with the clinician. The story may also cause issues to surface which are beyond the clinician's scope of practice and therefore warrant referral to a relevant source.

- Some clients have difficulty telling a story and they can be assisted through reflective diary keeping, free writing and including artefacts (letters, poems, drawings). In a multilingual context, clients should be provided with opportunities to share their stories in the language/s in which they feel most comfortable, allowing them the freedom to use informal language, gesture, code mixing and switching to enhance their story telling. Some clients are not candidates for this type of narrative methodology and therefore the clinician needs to decide on its use on a case-by-case basis.

- The clinician has the task of placing the story within a larger sociocultural context and should probe the temporal and social contexts during which critical events occurred. For example, the stories in this study were shared by participants who lived through apartheid in South Africa and their experiences as people who stuttered were also shaped by their broader social reality. For some, discrimination was not experienced only as a consequence of stuttering, but also by virtue of their race. Some participants reported their experiences during a particular era when schools took the view that children should be 'seen and not heard' and illuminated how this reality shaped their experience of stuttering.

By listening to the story, the clinician should be able to identify the patterns of self-identity formations evident in the client's story. For example, are the two formations Able and DisOther evident in the story? When do they occur in the story - across context and time; which is the dominant self-identity strand? This mapping would allow the clinician to interpret the client's behaviour as part of his/her selfidentity formation, i.e. what he/she does is related to who he/she is in a particular context. For example, if a client has a self-identity as DisOther in a classroom, he/she may be silent in an attempt to pass for normal - his/her behaviour therefore is part of his identity management. A mapping of the self-identity formations will also assist the clinician in targeting the contexts for intervention and appreciating that different strategies may be necessary across contexts.

\section{Understanding the power dynamics}

This study illuminated that while the individual can have both positive and negative understandings of themselves, when in a competing relationship they cause issues of conflict, power and ambivalence to surface, i.e. political dimension. This power struggle within and against oneself speaks to a layer of struggle that is an inherent part of the experience. The client must therefore be empowered to negotiate his/ her own internal power struggle as part of a repertoire of skills to enable the desired intervention outcome. When using self-identity as a lens the clinician is obliged to ask questions such as: Which of the self-identities is dominant and why? How can the ambivalence between self-identities be creatively managed? How can the relationship between self-identity formations shift from a competing to harmonising relationship?

\section{Narrative intervention}

This study was not intervention-based. However, narrative approaches to intervention may be useful in facilitating self-change in adults who stutter. The methodology is derived from constructivist theory based on the assumption that people have the ability to deconstruct and reconstruct themselves to create new realities. The advantage of the narrative approach is that the client can create a personally meaningful intervention by connecting his/her past with his/her future by determining the desired outcomes and realities within his/her range of competence (Biggs \& Hinton-Bayre, 2008).

The alternative story is seen as an opportunity for the client to gain greater control of their lives by constructing different views of themselves and taking the necessary actions to achieve a new vision. There are different ways of achieving the alternative story. For example, Polkinghorne (1996) explained that clients described life plots that were agentic or victimic. In the victimic plot, which is similar to self-identity as DisOther, a person constructed him/herself in a negative way and was characterised by blame and lack of progressive movement. In contrast, the agentic life plot was one in which the person was actively engaged in advancing towards an attainable goal. The task of the clinician was to assist the client in uniting all the elements of his/her life into a story that reveals his/her identity and actions and then to challenge and confront the victimic plot through a process by which he/she detaches him/herself from the story as he/she creates a new story coupled with relevant action.

DiLollo et al. (2002) used narrative therapy in stuttering intervention, based on the rationale that therapy outcomes are more likely to be successful and sustainable when the self is deconstructed from the stuttering-dominated self to the self that takes on the fluent speaker role. They provide a useful narrative methodology to achieve this.

\section{Appreciation of fuller self-identity}

In contrast to DiLollo et al. (2002), who focus on the fluent speaker role in the self-reconstruction process, the authors of this paper offer different perspectives on the reconstruction process and fluent speaker role. Self-construction/reconstruction does not limit the Able identity only to a fluent speaking role. The Able identity (Kathard, 2006) is crafted from a more all-embracing positive sense of self which includes the role as better communicator and fluent speaker but is not limited to it. The clinical implication is therefore that while fluency and improved communication are part of a positive self-identity there are other personal successes like being in a position of power, successful at work and relationships that empower individuals and drive a positive change. The clinician should therefore capitalise on an asset-based approach by focusing on strengths to build on. This perspective offers the possibility of constructing and acknowledging a more complete Able self-identity and using it as a catalyst to drive further positive self-construction including that of good communicator/fluent speaker. The self as Able is more robust and resilient and therefore not easily disrupted or dislodged by episodes of stuttering as the person has a wide-ranging resource base of skills including communication skills.

Furthermore, while other studies promote fluency and attainment of a self-concept as a fluent speaker as the end goal of intervention, this study suggests that there are different ways of living positively with impairment. Self as DisOther and Able could coalesce - allowing the idea of one within the other - a coalition of opposites. It is suggestive of a compassionate living of different selves, acknowledging that DisOther is part of one's story but not the only story.

Finally, the findings have implications for relapse. While fluency has traditionally been used as an indicator of relapse, Perkins (1979) argued that lapses in self-identity as a stutterer would be a more robust indicator than the narrow confines of maintaining fluent speech. In agreement with Perkins, the authors of this paper tentatively suggest 
that a lapse or a dislodging of self-identity as Able and the resurgence and strengthening, of self-identity as DisOther, together with negative identity management strategies e.g. avoidance, or concealing stuttering to pass for normal, are other indicators of relapse. Therefore, the aim of interventions should focus on strengthening self-identity as a basis for improved communication.

\section{Focus of change: self and society}

While intervention efforts focus on the individual as the locus of change, this study also points to the powerful social system which constructs stuttering in a negative light. People who stutter live in environments which have negative views of stuttering and hold general negative stereotypes of stuttering (Blood, Blood, Tellis \& Gabel, 2003). Society plays a critical role in shaping both positive and negative selfidentities. While we might continue to work with the individual, the clinician is equally challenged to change the attitudes of society to become accepting of people who stutter for who they are - as people (who stutter) - as part of a continuum of diversity.

\section{Acknowledgements}

We thank the participants for generously sharing their stories and express our gratitude to the National Research Foundation (South Africa) for supporting the project financially.

\section{References}

Angen, M. J. (2000). Evaluating interpretive inquiry: Reviewing the validity debate and opening the dialogue. Qualitative Health Research, 10(3), 378-395.

Bakhtin, M. M. (1981). The dialogical imagination. Austin, TX: University of Texas Press.

Begley, C. M. (1996). Using triangulation in nursing research. Journal of Advanced Nursing, 24, 122-128.

Bhatia, S., \& Ram, A. (2001). Acculturation, dialogical voices and the construction of the diasporic self. Commentary: Culture and Psychology, 7, 297-309.

Biggs, H. C., \& Hinton-Bayre, A. D. (2008). Telling tales to end wails: Narrative therapy techniques and rehabilitation counseling. Australian Journal of Rehabilitation Counselling, $14(1), 16-25$.

Blood, G. W., Blood, I. M., Tellis, G. M., \& Gabel, R. M. (2003). A preliminary study of selfesteem, stigma, and disclosure in adolescents who stutter. Journal of Fluency Disorders, 28, 143-159.

Boehmer, E. (1995), Colonial and postcolonial literature. Oxford: Oxford University Press.

Charmaz, K. (1995). Grounded theory. In J. A. Smith, R. Harre \& L. van Langenhove (Eds.), Rethinking methods in psychology (pp. 27- 49). London: Sage.

Clandinin, D. J., \& Connelly, F. M. (1994). Personal experience methods. In N. K. Denzin \& Y. Lincoln (Eds.), Handbook of qualitative research (pp. 413-427). Thousand Oaks, CA: Sage.

Cresswell, J. W., \& Miller, D. L. (2000). Determining validity in qualitative inquiry. Theory into Practice, 39(3), 124-130.

DiLollo, A., Niemeyer, R. A., \& Manning W. H. (2002). A personal construct view of relapse: Indications for a narrative component to stuttering treatment. Journal of Fluency Disorders, 27, 19-42.

DiLollo, A., \& Wolter, J. (2004). Qualitative research in communication disorders. The ASHA Leader, 9 (June 11), 4-5, 16-17.

Evesham, M., \& Fransella, F. (1985). Stuttering relapse: The effect of combined speech and psychological reconstruction programme. British Journal of Disorders of Communication, 20, 237-248.

Fransella, F. (1968). Self-concepts and the stutterer. British Journal of Psychiatry, 114, 15311535.

Fransella, F. (1972). Stuttering: Not a symptom but a way of life. International Journal of Language and Communication Disorder, 5(1), 22-29.
Freeman, D. (1996). To take them at their word: Language data in the study of teacher's knowledge. Harvard Educational Review, 66(4), 732-761.

Hagstrom F., \& Wertsch, J. V. (2004). Grounding social identity for professional practice. Topics in Language Disorders, 24(4), 162-173.

Hatch, J. A., \& Wisniewski, R. (1995). Life history and narrative: Questions, issues and exemplary works. In J. A. Hatch \& R. Wisniewski (Eds.), Life history and narrative (pp. 113-137). London: Falmer Press.

Hermans, H. J. M. (2002). The dialogical self as a society of mind: Introduction. Theory \& Psychology, 12(2), 147-160.

James, W. (1982). The varieties of religious experience. A study in human nature (Gifford Lectures in Natural Religion delivered at Edinburgh, 1901-1902). New York: Penguin Press.

Kathard, H. (2003). Life histories of people who stutter: On becoming someone. Unpublished doctoral thesis, University of Durban-Westville, KwaZulu-Natal, South Africa.

Kathard, H. (2006). On becoming someone. Self-identity as Able: Life histories of people who stutter. Advances in Speech-language Pathology, 8(2), 79-91.

Kathard, H. (2009). Personal truth making. A cautious celebration. In R. Dhanpath \& M Samuel (Eds.), Life history research: Epistemology, methodology and representation (pp. 1836). Rotterdam: Sense Publishers.

Kathard, H., Pillay, M., Samuel, M., \& Reddy, V. (2004). Genesis of self-identity as DisOther South African Journal of Communication Disorders, 41, 3-14.

Kelly, G. A. (1955). The psychology of personal constructs (Vol I \& II). Norton.

Knafl, K. A., \& Breitmayer, B. J. (1991). Triangulation in qualitative research issues of conceptual clarity and purpose. In J. M. Morse (Ed.), Qualitative nursing research: A contemporary dialogue (pp. 226-239). Thousand Oaks, CA: Sage.

Lincoln, Y. S., \& Guba, E. G. (1985). Naturalistic inquiry. Thousand Oaks, CA: Sage.

Measor, L., \& Sikes, P. (1992). Visiting lives: Ethics and methodology in life history. In I. F. Goodson (Ed.), Studying teachers' lives (pp. 209-233). New York: Teachers College Press.

Miles, M. B., \& Huberman, A. M. (1994). Qualitative data analysis: An expanded sourcebook (2nd ed.). Thousand Oaks, CA: Sage.

Mishler, E. G. (1999). Storylines: Craftartists' narratives of identity. London: Harvard University Press.

Perkins, W. H. (1979). From psychoanalysis to discoordination. In H. H. Gregory (Ed.), Controversies about stuttering therapy (pp. 97-127). Baltimore, MD: University Park Press.

Petrunik, M., \& Shearing, C. D. (1983). Fragile façade: Stuttering and the strategic manipulation of awareness. Social Problems, 31(2), 125-136.

Plummer, K. (2001). Documents of life 2: An invitation to critical humanism. London: Sage.

Polkinghorne, D. E. (1996). Explorations of narrative identity. Psychological Inquiry, 7, 363 367.

Rubin, H. J., \& Rubin, I. (1995). Qualitative interviewing: The art of hearing data. London: Sage.

Salgado, J., \& Hermans, H. J. M. (2005). The return of subjectivity: From a multiplicity of selves to the dialogical self. E-Journal of Applied Psychology: Clinical section, 1(1), 3-13. http://ojs. lib.swin.edu.au/index.php/ejap.

Samuel, M. (2009). On becoming a teacher: Life history research and the force-field model of teacher development. In R. Dhanpath \& M. Samuel (Eds.), Life history research Epistemology, methodology and representation (pp. 1-16). Rotterdam: Sense Publishers.

Sen, A. (2006). Identity and violence: The illusion of destiny. London: WW Norton \& Co.

Shearer, W. M. (1961). A theoretical consideration of the self-concept and body image in stuttering therapy. American Speech \& Hearing Association, 3, 115-116.

Sheehan, J. G. (1970). Stuttering: Research and theory. New York: Harper.

Silverman, E. (2001, October). Consumer alert: Stuttering and gender research. Paper presented at 4 th International Stuttering Awareness Day Conference (on-line conference). Retrieved from http://www.mnsu.edu/dept/comradis/isad4/papers/silverman2.html

Somers, M. R. (1994). The narrative constitution of identity: relational and network approach. Theory and Society: Renewal and critique in social theory, 23(5), 604-635.

Stewart, T., \& Birdsall, M. (2001). A review of the contribution of personal construct psychology to stammering therapy. Journal of Constructivist Psychology, 14, 215-226.

Tetnowski, J. A., \& Damico, J. S. (2001). A demonstration of the advantages of qualitative methodologies in stuttering research. Journal of Fluency Disorders, 26(1), 17-42.

Valsiner, J. (2002). Forms of dialogical relations and semiotic autoregulations within the self. Theory \& Psychology, 12(2), 251-265. 